\title{
Long-Term Clinical Outcome of Cardiogenic Shock Patients Undergoing Impella CP Treatment vs. Standard of Care
}

\author{
Clemens Scherer ${ }^{1,2,+}{ }^{1}$, Enzo Lüsebrink ${ }^{1,2,+}+$, , Danny Kupka ${ }^{1,2}$, Thomas J. Stocker ${ }^{1,2}$, \\ Konstantin Stark ${ }^{1,2}$, Christopher Stremmel ${ }^{1,2}$, Mathias Orban ${ }^{1,2}$, Tobias Petzold ${ }^{1,2} \mathbb{D}$, \\ Antonia Germayer 1,2, Katharina Mauthe ${ }^{1,2}$, Stefan Kääb ${ }^{1,2}$, Julinda Mehilli 1,2 (D, \\ Daniel Braun ${ }^{1,2}$, Hans Theiss ${ }^{1,2}$, Stefan Brunner ${ }^{1,2}$, Jörg Hausleiter ${ }^{1,2}$, Steffen Massberg 1,2 \\ and Martin Orban 1,2,*(iD) \\ 1 Intensive Care Unit and Department of Cardiology, Medizinische Klinik und Poliklinik I, Klinikum der \\ Universität München, 81377 Munich, Germany; clemens.scherer@med.uni-muenchen.de (C.S.); \\ e.luesebrink@med.uni-muenchen.de (E.L.); danny.kupka@med.uni-muenchen.de (D.K.); \\ thomas.stocker@med.uni-muenchen.de (T.J.S.); konstantin.stark@med.uni-muenchen.de (K.S.); \\ christopher.stremmel@med.uni-muenchen.de (C.S.); mathias.orban@med.uni-muenchen.de (M.O.); \\ tobias.petzold@med.uni-muenchen.de (T.P.); antonia.germayer@med.uni-muenchen.de (A.G.); \\ katharina.mauthe@med.uni-muenchen.de (K.M.); stefan.kaab@med.uni-muenchen.de (S.K.); \\ julinda.mehilli@med.uni-muenchen.de (J.M.); daniel.braun@med.uni-muenchen.de (D.B.); \\ Hans.Theiss@med.uni-muenchen.de (H.T.); stefan.brunner@med.uni-muenchen.de (S.B.); \\ joerg.hausleiter@med.uni-muenchen.de (J.H.); steffen.massberg@med.uni-muenchen.de (S.M.) \\ 2 DZHK (German Center for Cardiovascular Research), Partner Site Munich Heart Alliance, \\ Medizinische Klinik und Poliklinik I, Klinikum der Universität München, 81377 Munich, Germany \\ * Correspondence: MartinOrban@gmail.com or Martin.Orban@med.uni-muenchen.de; \\ Tel.: +49-(0)-4400-75221 \\ + Both authors contributed equally.
}

Received: 28 September 2020; Accepted: 21 November 2020; Published: 24 November 2020

\begin{abstract}
The number of patients treated with the mechanical circulatory support device Impella Cardiac Power (CP) for cardiogenic shock is steadily increasing. The aim of this study was to investigate long-term survival and complications related to this modality. Patients undergoing Impella CP treatment for cardiogenic shock were retrospectively enrolled and matched with cardiogenic shock patients not treated with mechanical circulatory support between 2010 and 2020. Data were collected from the cardiogenic shock registry of the university hospital of Munich (DRKS00015860). 70 patients with refractory cardiogenic shock without mechanical circulatory support were matched with 70 patients treated with Impella CP. At presentation, the mean age was $67 \pm 15$ years with $80 \%$ being male in the group without support and $67 \pm 14$ years $(p=0.97)$ with $76 \%$ being male $(p=0.68)$ in the group with Impella. There was no significant difference in the rate of cardiac arrest $(47 \%$ vs. $51 \%, p=0.73$ ) and myocardial infarction was the predominant cause of cardiogenic shock in both groups $(70 \%$ vs. $77 \%)$. A total of $41 \%$ of patients without cardiocirculatory support and $54 \%$ of patients with Impella support died during the first month $(p=0.17)$. After one year, mortality rates were similar in both groups (55\% in conventional vs. $59 \%$ in Impella CP group, $p=0.30$ ) as was mortality rate at long-term 5 -years follow-up ( $64 \%$ in conventional vs. $73 \%$ in Impella CP group, $p=0.33$ ). The rate of clinically significant bleedings during ICU stay was lower in the conventional group than in the Impella support group $(15 \%$ vs. $43 \%, p=0.002)$. In this small observational and non-randomized analysis no difference in long-term outcome between patients treated with Impella $\mathrm{CP}$ vs. guideline directed cardiogenic shock therapy without mechanical circulatory support could be detected. Care must be taken regarding the high rate of bleeding and vascular complications when using Impella CP. Large, adequately powered studies are urgently needed to investigate the efficacy and safety of Impella CP in cardiogenic shock.
\end{abstract}


Keywords: cardiogenic shock; mechanical circulatory support; Imella

\section{Introduction}

Cardiogenic shock is still the major driver of mortality in cardiac intensive care units (ICU) and complicates around $10 \%$ of myocardial infarctions with contemporary 30-day and 1-year mortality up to $52 \%$ and $57 \%$ according to the latest large scale randomized trials (IABP II [1,2], CULPRIT-SHOCK trial [3, 4]). Contemporary registries reported mortality rates ranging from $45-70 \%[5,6]$. Cardiogenic shock as defined by the European Society of Cardiology (ESC) is specified by hypotension despite adequate filling status (systolic blood pressure $<90 \mathrm{mmHg}$ ) with signs of hypoperfusion (clinical: cold sweated extremities, oliguria, mental confusion, dizziness, narrow pulse pressure; laboratory: metabolic acidosis, elevated serum lactate, elevated serum creatinine) due to primary cardiac dysfunction $[7,8]$. A significant subgroup of cardiogenic shock patients cannot be stabilized by guideline-directed volume and medical treatment alone. Here, mechanical circulatory support devices, in particular venoarterial extracorporeal membrane oxygenation (VA-ECMO) and Impella Cardiac Power (CP) transvalvular microaxial flow pump (Abiomed, Danvers, Massachusetts) [9] have emerged as established interventions [10-12].

The numbers of patients undergoing Impella CP treatment for cardiogenic shock rapidly increased during the last years due to its broad availability and easiness of insertion. However, there is only one small prospective randomized trial, the IMPRESS-IN-SEVERE-SHOCK trial which compared efficacy and safety of the Impella CP vs. intra-aortic balloon pump (IABP) in patients with acute myocardial infarction complicated by cardiogenic shock (AMICS) and did not show any survival benefit in the 48 patients included [13]. Numerous retrospective trials investigated acute and few mid-term outcomes of cardiogenic shock patients treated with Impella with maximum follow-up of 1 year [14] with 30-day mortality rates ranging from $36-52 \%$ [14-17]. Studies were also mixing different types of Impella, namely Impella 2.5, CP and 5.0 [18-20].

Hence, data on long-term outcome of cardiogenic shock patients exclusively undergoing Impella $\mathrm{CP}$ treatment are sparse and the first adequately powered randomized, multicenter Danish-German Cardiogenic Shock trial (NCT01633502) comparing Impella treatment with conventional guideline treatment alone [21] is ongoing and still far from finalization.

\section{Methods}

\subsection{Study Population}

In compliance with the Declaration of Helsinki and German data protection laws, cardiogenic shock patients treated in cardiac intensive care unit (ICU) of two Ludwig-Maximilians-University (LMU) hospitals, Campus Großhadern and Campus Innenstadt, between 2010 and 2020 were included in a registry (LMUshock). The latter is registered at the WHO International Clinical Trials Registry Platform (DRKS00015860) and was approved by the local ethics committee (IRB number: 18-001). The inclusion criterion of this registry was cardiogenic shock according to the IABP-SHOCK II trial definition: hypotension despite adequate filling status (systolic blood pressure $<90 \mathrm{mmHg}$ for $30 \mathrm{~min}$ or catecholamines to maintain systolic blood pressure $>90 \mathrm{mmHg}$ ), clinical pulmonary congestion and impaired end-organ perfusion with at least one of the following criteria: altered mental status, cold, clammy skin and extremities, oliguria, elevated serum lactate level due to primary cardiac dysfunction [22]. For this study, patients (a) with ECMO- or IABP-treatment, (b) undergoing Impella support for high risk percutaneous coronary intervention (PCI), so called "protected PCI", (c) undergoing treatment with Impella 2.5 or 5.0, (d) pericardial tamponade as cause of cardiogenic shock and (e) with missing data were excluded from this analysis. To adjust for confounders, patients with Impella CP support were matched by propensity score with patients without Impella CP support 
in a 1:1 ratio. Following patient consent, phone calls were performed to collect post-discharge clinical endpoints.

\subsection{Patient Management during Impella Treatment}

Details on Impella CP implantation have been reported previously [13]. Briefly, Impella CP implantation was exclusively performed in the catheterization laboratory under fluoroscopic control. The Impella CP catheter is a micro-axial continuous flow rotor pumps that can provide forward flow of up to $3.7 \mathrm{l} / \mathrm{min}$. The device is recommended for insertion via femoral artery. A pigtail catheter is inserted into the left ventricle (LV) followed by introduction of a 0.18-inch Platinum Plus 260 $\mathrm{cm}$ guidewire (Boston Scientific, Natick, MA, USA) into LV to exchange the Impella CP catheter. The Impella is advanced over the guidewire into LV, wire is removed, and device support is initiated using the automated Impella Controller. Thereafter rotor speed is adjusted automatically to provide optimal forward flow or can be adjusted manually to desired performance level. Unfractionated heparin was intravenously administered to achieve an activated partial thromboplastin time above 60 $\mathrm{s}$ in the absence of bleeding complications. All patients were weaned at the discretion of the attending physician. Impella CP decannulation was routinely performed at bedside with compression of the arterial access site using a compression system.

\subsection{Study Endpoints}

Ischemic (death, myocardial infarction, stent thrombosis, stroke, vascular complications) and bleeding events (classified according to the bleeding academic research consortium (BARC)) [23] during hospital stay and at the latest possible follow-up were obtained and analyzed. To evaluate the neurologic outcome Pittsburgh Cerebral Performance Category (CPC) at ICU discharge was determined.

\subsection{Statistical Analysis}

Statistical analysis was performed using R (version 4.0.1, The R foundation, Vienna, Austria). Normally distributed continuous variables were reported as mean with standard deviation and non-normally distributed continuous variables as median with interquartile ranges (25th and 75th percentile). To compare two groups, paired and unpaired t-test for normally distributed continuous variables and paired and unpaired Mann-Whitney-U test for non-normally distributed continuous variables were used. Categorical variables were reported as absolute numbers and percentages. To compare unpaired groups, chi-squared test was utilized. For matched paired groups, McNemar's test was used. All tests were 2 -tailed, and $p$-values $<0.05$ were considered as significant. Mortality and bleeding rates were calculated using the Kaplan-Meier method and comparisons were made by using log-rank tests. For propensity score matching, the R package "MatchIt" version 3.0.2 was utilized with a 1:1 nearest neighbor algorithm, no replacement, logistic link distance measure and a caliper of 0.1 [24]. The following baseline parameters which are known to impact ICU mortality in cardiogenic shock were used for matching: Age, gender, first measured lactate measured at ICU admission, ventilation on ICU, myocardial infarction at presentation and cardiac arrest $[16,25]$. The propensity score was estimated by logistic regression. After matching standard difference of mean was below 0.1 for all parameters. To assess the correlation of clinical and laboratory parameters with mortality, univariate and multivariate Cox proportional hazard models were used. Covariates included age, diabetes, hypertension, first measured lactate on ICU, first measured GFR on ICU, cardiac arrest, Impella treatment and myocardial infarction. Stepwise selection of parameters for multivariate analysis was performed by Akaike information criterion (AIC) with backward direction and 1000 bootstrap iterations using the stepAIC function of the R package MASS (version 7.3-51.6). 


\section{Results}

\subsection{Study Population and Baseline Characteristics}

Registry data of 826 patients with cardiogenic shock treated in two cardiologic ICUs between 2010 and 2020 were available. After exclusion of patients according to exclusion criteria, 76 patients with Impella support were considered eligible for matching (Study Flow chart, Figure 1). Due to six missing matching partners when using a caliper of 0.1 for matching, 70 patients with Impella support were matched with 70 patients without mechanical circulatory support as described above, achieving a standard difference of mean below 0.1 for all matching parameters (Supplementary Figure S1).

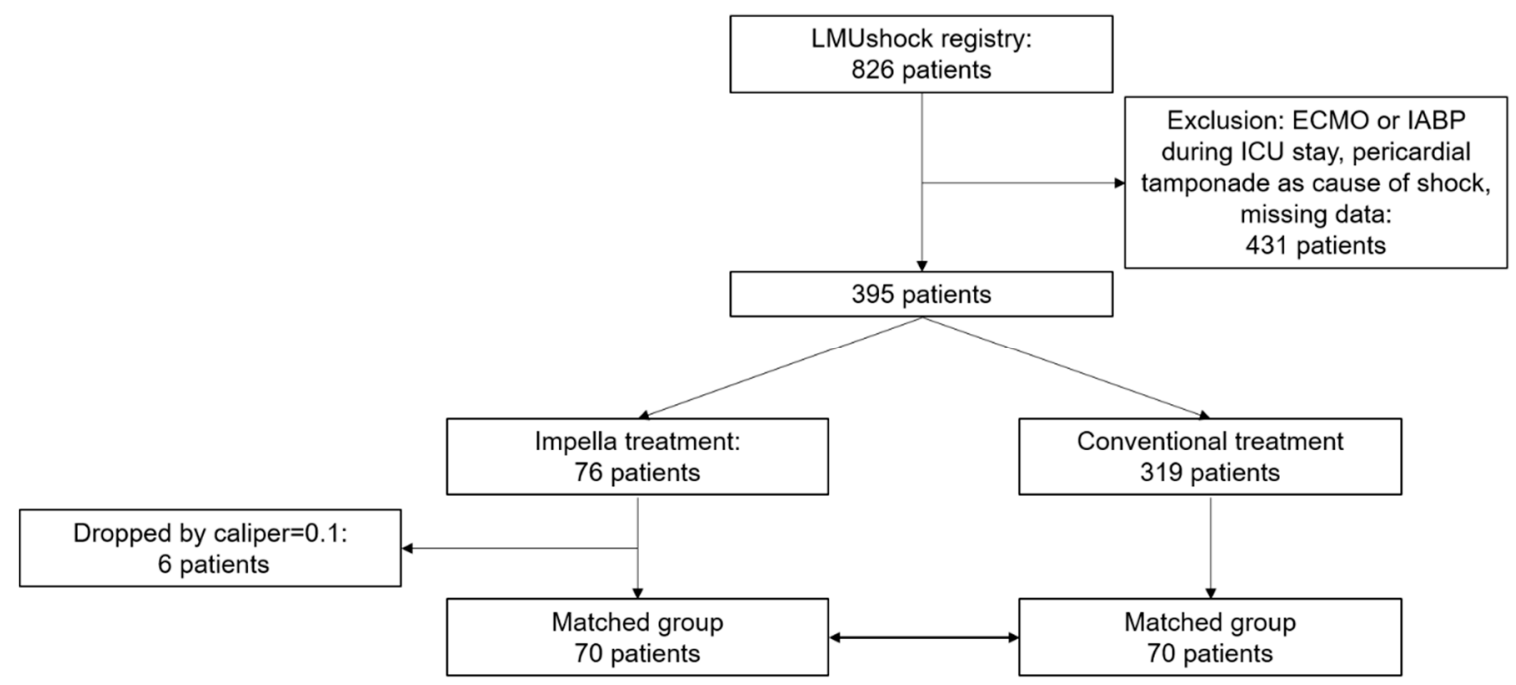

Figure 1. Study Flow chart. Flow diagram depicting patient selection.

At presentation, the mean age was $67 \pm 15$ years with $80 \%$ being male in the group without support and $67 \pm 14$ years $(p=0.97)$ with $76 \%$ being male $(p=0.68)$ in the group with Impella. Cardiovascular diseases and cardiovascular risk factors before onset of cardiogenic shock were distributed evenly. There was no significant difference in the rate of cardiac arrest (47\% vs. 51\%, $p=0.73)$, duration of cardio-pulmonary resuscitation if applicable [minutes] (median 24.0, interquartile range (IQR) $(9.5,52.5)$ vs. $19.0(1.0,26.5), p=0.22)$. Myocardial infarction was the predominant cause of cardiogenic shock in both groups (70\% vs. 77\%). The baseline characteristics of both groups are displayed in Table 1. Patients' characteristics before matching are shown in Supplementary Table S1.

Table 1. Baseline characteristics of matched patients.

\begin{tabular}{|c|c|c|c|c|}
\hline Variables & $\begin{array}{l}\text { Conventional } \\
\quad(n=70)\end{array}$ & $\begin{array}{l}\text { Impella } \\
(n=70)\end{array}$ & $\begin{array}{l}p \text { Value } \\
\text { (Paired) }\end{array}$ & $\begin{array}{c}p \text { Value } \\
\text { (Not Paired) }\end{array}$ \\
\hline Age in years, mean (SD) & $67.3(14.8)$ & $67.2(14.1)$ & 0.97 & 0.97 \\
\hline Male gender, $n(\%)$ & $56(80.0)$ & $53(75.7)$ & 0.68 & 0.68 \\
\hline Body mass index, mean (SD) & $27.6(5.6)$ & $27.3(4.5)$ & 0.79 & 0.77 \\
\hline Coronary artery disease, $n(\%)$ & $41(58.6)$ & $47(67.1)$ & 0.39 & 0.38 \\
\hline Previous myocardial infarction, $n(\%)$ & $23(32.9)$ & $17(24.3)$ & 0.36 & 0.35 \\
\hline Previous PCI, $n(\%)$ & $22(31.4)$ & $25(35.7)$ & 0.74 & 0.72 \\
\hline Previous CABG, $n(\%)$ & $4(5.7)$ & $2(2.9)$ & 0.68 & 0.68 \\
\hline Atrial fibrillation, $n(\%)$ & $25(35.7)$ & $20(28.6)$ & 0.49 & 0.47 \\
\hline Previous stroke, $n(\%)$ & $8(11.4)$ & $9(12.9)$ & 1.00 & 1.00 \\
\hline Peripheral artery disease, $n(\%)$ & $17(24.3)$ & $12(17.1)$ & 0.46 & 0.40 \\
\hline
\end{tabular}


Table 1. Cont.

\begin{tabular}{|c|c|c|c|c|}
\hline Variables & $\begin{array}{l}\text { Conventional } \\
\qquad(n=70)\end{array}$ & $\begin{array}{l}\text { Impella } \\
(n=70)\end{array}$ & $\begin{array}{l}p \text { Value } \\
\text { (Paired) }\end{array}$ & $\begin{array}{c}p \text { Value } \\
\text { (Not Paired) }\end{array}$ \\
\hline Smoker, $n(\%)$ & - & - & \multirow{4}{*}{0.95} & \multirow{4}{*}{0.94} \\
\hline Active smoker & $16(22.9)$ & $17(24.3)$ & & \\
\hline Former smoker & $16(22.9)$ & $17(24.3)$ & & \\
\hline Never smoked & $38(54.3)$ & $36(51.4)$ & & \\
\hline Hypertension, $n$ (\%) & $51(72.9)$ & $48(68.6)$ & 0.71 & 0.71 \\
\hline High cholesterol, $n(\%)$ & $42(60.0)$ & $32(45.7)$ & 0.11 & 0.13 \\
\hline Diabetes, $n(\%)$ & $23(32.9)$ & $23(32.9)$ & 1.00 & 1.00 \\
\hline Positive cardiovascular family history, $n(\%)$ & $8(11.4)$ & $11(15.7)$ & 0.63 & 0.62 \\
\hline $\begin{array}{c}\text { Simplified acute Physiology Score II-score, } \\
\text { median (IQR) }\end{array}$ & $68.6(58.2,76.0)$ & $68.6(62.5,76.8)$ & 0.53 & 0.45 \\
\hline Cardiac arrest, $n(\%)$ & $33(47.1)$ & $36(51.4)$ & 0.73 & 0.74 \\
\hline Out of hospital cardiac arrest, $n(\%)$ & $21(30.0)$ & $14(20.0)$ & 0.21 & 0.24 \\
\hline $\begin{array}{l}\text { Duration of cardio-pulmonary resuscitation if } \\
\text { applicable in minutes, median (IQR) }\end{array}$ & $24.0(9.5,52.5)$ & $19.0(1.0,26.5)$ & NA & 0.22 \\
\hline Cause of cardiogenic shock, $n(\%)$ & - & - & \multirow{8}{*}{ NA } & \multirow{8}{*}{0.38} \\
\hline STEMI & $25(35.7)$ & $28(40.0)$ & & \\
\hline NSTEMI & $24(34.3)$ & $26(37.1)$ & & \\
\hline Cardiomyopathy & $13(18.6)$ & $13(18.6)$ & & \\
\hline Myocarditis & $1(1.4)$ & $2(2.9)$ & & \\
\hline Arrhythmia & $3(4.3)$ & $0(0.0)$ & & \\
\hline Valvular & $1(1.4)$ & $0(0.0)$ & & \\
\hline Other & $3(4.3)$ & $1(1.4)$ & & \\
\hline PCI during hospital stay, $n(\%)$ & $44(62.9)$ & $53(75.7)$ & 0.10 & 0.14 \\
\hline CABG during hospital stay, $n(\%)$ & $1(1.4)$ & $0(0.0)$ & 1.00 & 1.00 \\
\hline
\end{tabular}

\subsection{ICU Parameters}

The SAPS-II scores (median 68.6, IQR $(58.2,76.0)$ vs. $68.6(62.5,76.8), p=0.53)$ were almost identically between both groups. The median length of ICU stay was shorter in the conventional as compared to the Impella group [days] (median 3.5, IQR $(1.2,8.7)$ vs. $5.5(1.9,12.5), p=0.04)$. There was no difference in the rate of mechanical ventilation $(74 \%$ vs. $77 \%, p=0.82)$. Systolic blood pressure was similar [mmHg] (median 108, IQR $(101,117)$ vs. $107(101,114), p=0.67)$ in both groups. Patients in the control group had a significant lower diastolic blood pressure [mmHg] (median 57, IQR $(50,60)$ vs. $60(57,66), p<0.01)$ and a lower average heart rate [bpm] (median 84 , IQR $(77,92)$ vs. $91(83,101)$, $p<0.01)$. The ICU parameters for both groups are displayed in Table 2. Medication at ICU discharge is displayed in Supplemental Table S2. Lactate levels are detailed in Supplementary Figures S2 and S3.

Table 2. ICU parameters.

\begin{tabular}{|c|c|c|c|c|}
\hline Variables & $\begin{array}{l}\text { Conventional } \\
\quad(n=70)\end{array}$ & Impella $(n=70)$ & $\begin{array}{l}p \text { Value } \\
\text { (Paired) }\end{array}$ & $\begin{array}{c}p \text { Value } \\
\text { (Not Paired) }\end{array}$ \\
\hline Duration of ICU stay in days, median (IQR) & $3.5(1.2,8.7)$ & $5.5(1.9,12.5)$ & 0.04 & 0.16 \\
\hline Average systolic blood pressure in $\mathrm{mmHg}$, median (IQR) & $107.7(100.9,116.5)$ & $107.4(100.5,113.5)$ & 0.67 & 0.57 \\
\hline Average diastolic blood pressure in $\mathrm{mmHg}$, median (IQR) & $56.6(49.9,60.0)$ & $59.5(56.8,65.7)$ & $<0.01$ & $<0.01$ \\
\hline Average heart rate in bpm, median (IQR) & $84.4(77.1,92.4)$ & $91.2(82.8,101.1)$ & $<0.01$ & $<0.01$ \\
\hline First lactate on ICU in mmol/L, median (IQR) & $3.5(1.6,7.5)$ & $3.4(1.9,7.5)$ & 0.82 & 0.72 \\
\hline First GFR on ICU in mL/min, median (IQR) & $49.6(30.2,60.0)$ & $49.2(37.2,60.0)$ & 0.89 & 0.97 \\
\hline Mechanical ventilation, $n(\%)$ & $52(74.3)$ & $54(77.1)$ & 0.82 & 0.84 \\
\hline ASS treatment, $n(\%)$ & $47(67.1)$ & $43(61.4)$ & 0.64 & 0.60 \\
\hline Clopidogrel treatment, $n(\%)$ & $30(42.9)$ & $34(48.6)$ & 0.62 & 0.61 \\
\hline Prasugrel treatment, $n(\%)$ & $21(30.0)$ & $16(22.9)$ & 0.44 & 0.44 \\
\hline Ticagrelor treatment, $n(\%)$ & $2(2.9)$ & $5(7.1)$ & 0.45 & 0.44 \\
\hline
\end{tabular}

\subsection{Clinical Endpoints}

A total of $41 \%$ of patients without cardiocirculatory support and $54 \%$ of patients with Impella support died during the first month $(p=0.17)$ (Figure 2A). After one year, mortality rates were similar in both groups ( $55 \%$ in conventional vs. $59 \%$ in Impella CP group, $p=0.30$ ) (Figure $2 \mathrm{~B}$ ) as was mortality rate at long-term 5 -years follow-up ( $64 \%$ in conventional vs. $73 \%$ in Impella $\mathrm{CP}$ group, $p=0.33$ ) (Figure 2C). 
+ Conventional + Impella

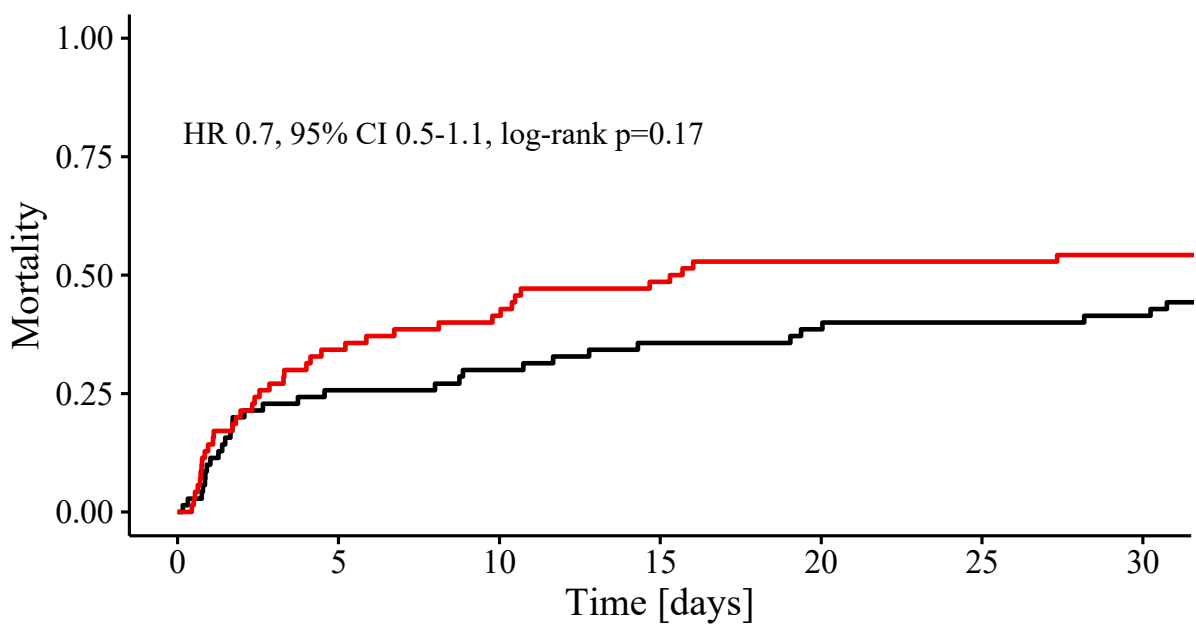

Number at risk

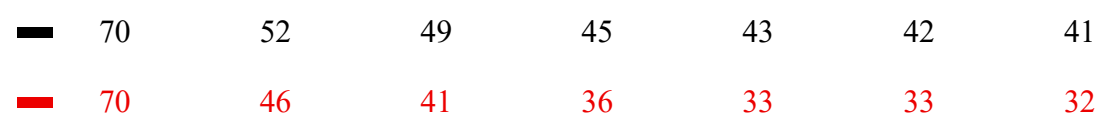

(A)

+ Conventional + Impella

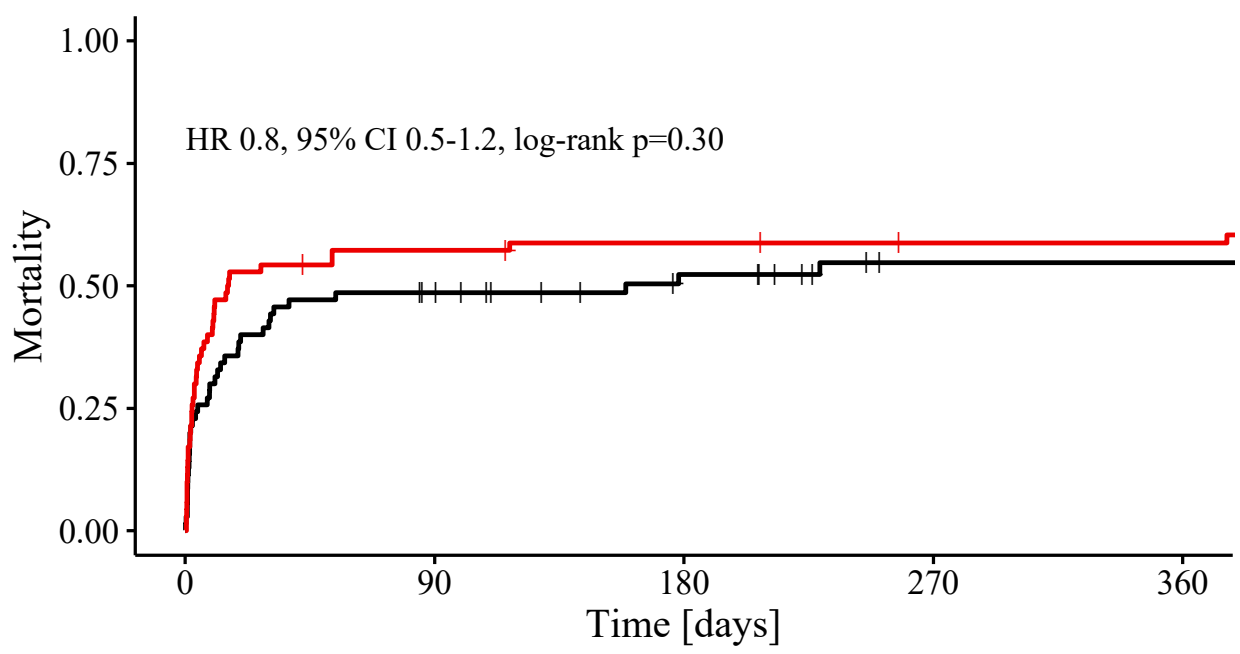

Number at risk

- 70

34

25

17

- 70

29

27

25

25

(B)

Figure 2. Cont. 
Conventional + Impella

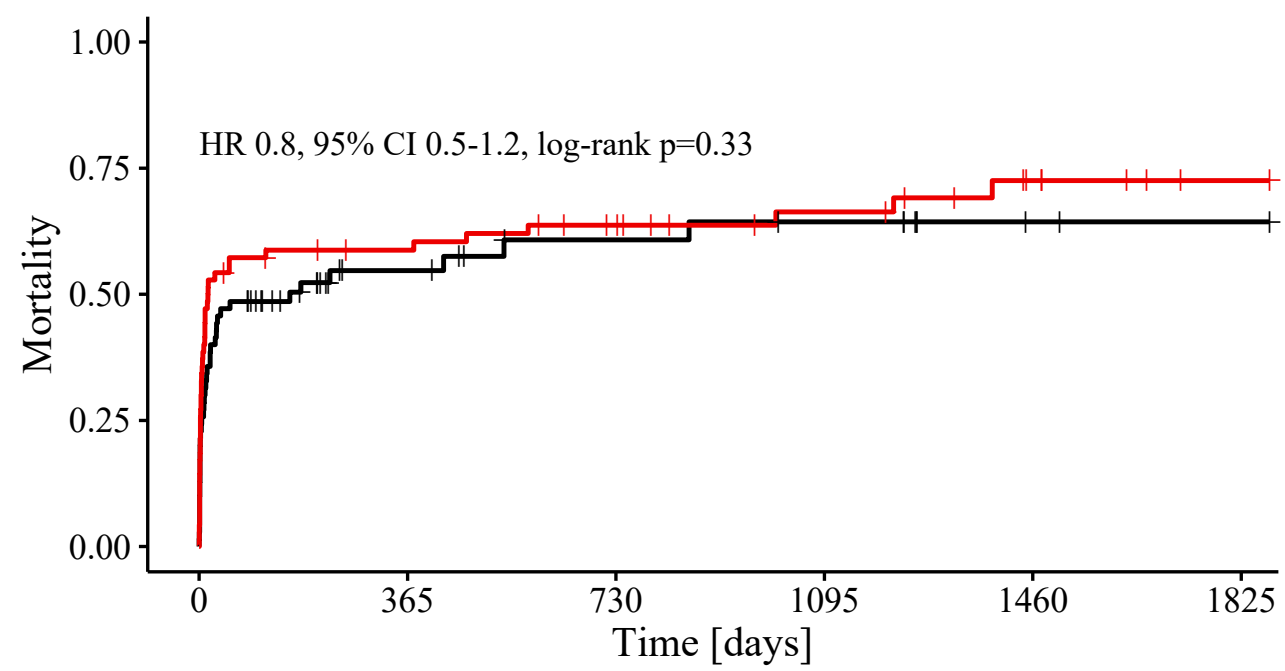

Number at risk

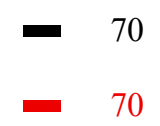

17

25
11

19

9

9

13
3

6
2

1

(C)

Figure 2. Mortality of patients with cardiogenic shock treated without cardiocirculatory support versus patients treated with Impella CP. Cumulative incidence curves of deaths for patients without cardiocirculatory support (black) and with Impella support (red) 30 days (A), 1 year (B) and 5 years (C) after the index event. Hazard ratio and $95 \%$ confidence interval is displayed for conventional group. $\mathrm{HR}$, hazard ratio; $\mathrm{CI}$, confidence interval.

The rate of any bleeding event during ICU stay ( $37 \%$ vs. $74 \%, p<0.001)$ (Figure $3 \mathrm{~A})$ as well as the rate of clinically significant bleedings classified as BARC 3 or higher was lower in the conventional group than in Impella CP group ( $15 \%$ vs. $43 \%, p=0.002$ ) (Figure $3 \mathrm{~B}$ ). There were no vascular complications in the control group whereas $7 \%$ of the patients in the Impella group $(p=0.07)$ suffered from vascular complications. 
- Conventional — Impella

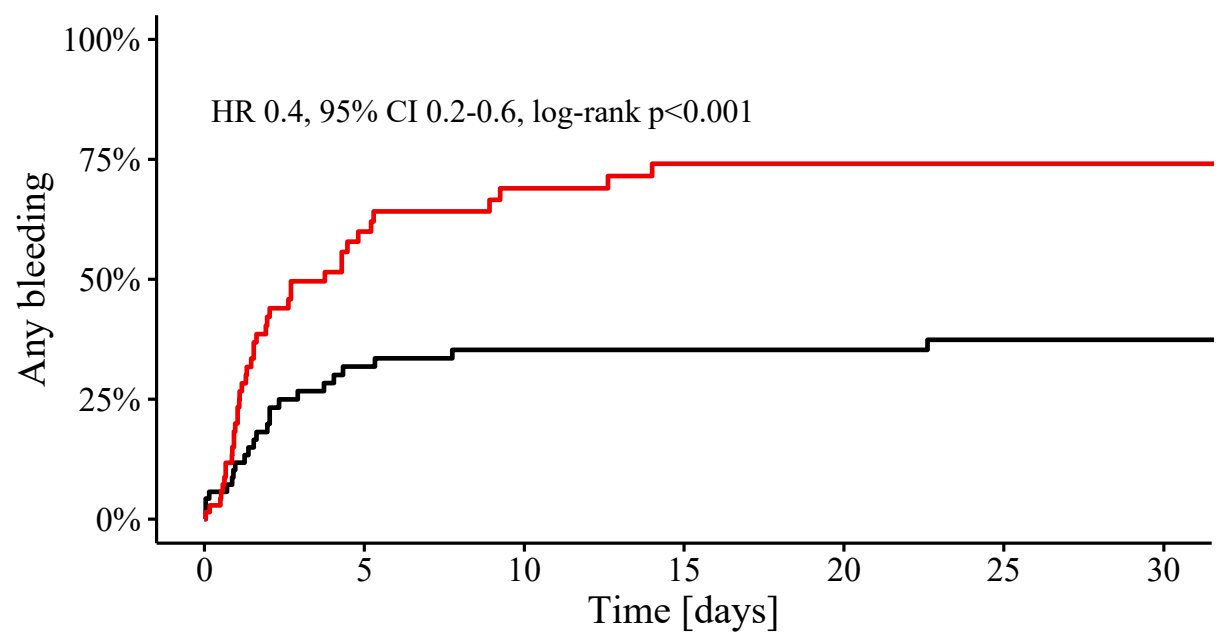

Number at risk

$\begin{array}{rrrrrrr}-70 & 39 & 35 & 33 & 32 & 30 & 29 \\ -\quad 70 & 19 & 13 & 9 & 9 & 9 & 9\end{array}$

(A)

- Conventional - Impella

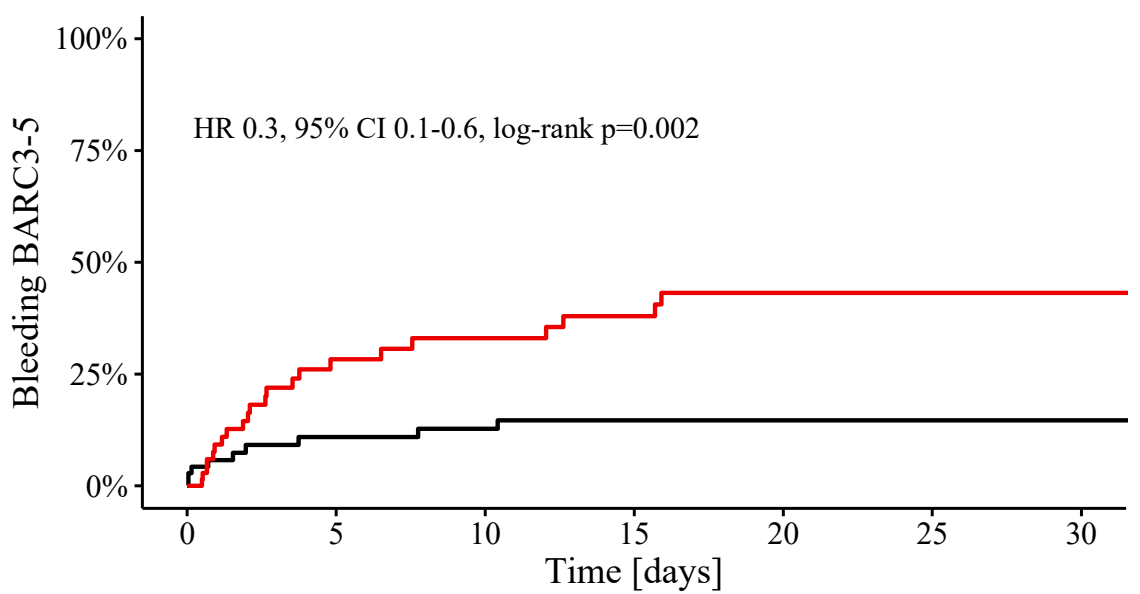

Number at risk

$\begin{array}{rrrrrrr}-70 & 49 & 45 & 40 & 38 & 37 & 36 \\ -\quad 70 & 32 & 28 & 24 & 22 & 22 & 22\end{array}$

(B)

Figure 3. Bleeding complications in patients treated without cardiocirculatory support versus patients treated with Impella CP. (A), Cumulative incidence curves of all bleedings occurring in patients without (black) and with Impella CP (red) are shown for 30 days after the index event. (B), Cumulative incidence curves of bleeding complications at least classified as BARC3 occurring in patients without (black) and with Impella CP (red) are shown for 30 days after the index event. HR and 95\% CI is displayed for conventional group. 
The neurologic outcome, measured as CPC score at discharge from ICU, was similar in both groups $(p=0.28)$ (Figure 4). All clinical endpoints are shown in Table 3.

In a Cox proportional hazard regression on long term-survival, we identified age, first measured lactate, first measured GFR on ICU and cardiac arrest as independent risk factors (Table 4).

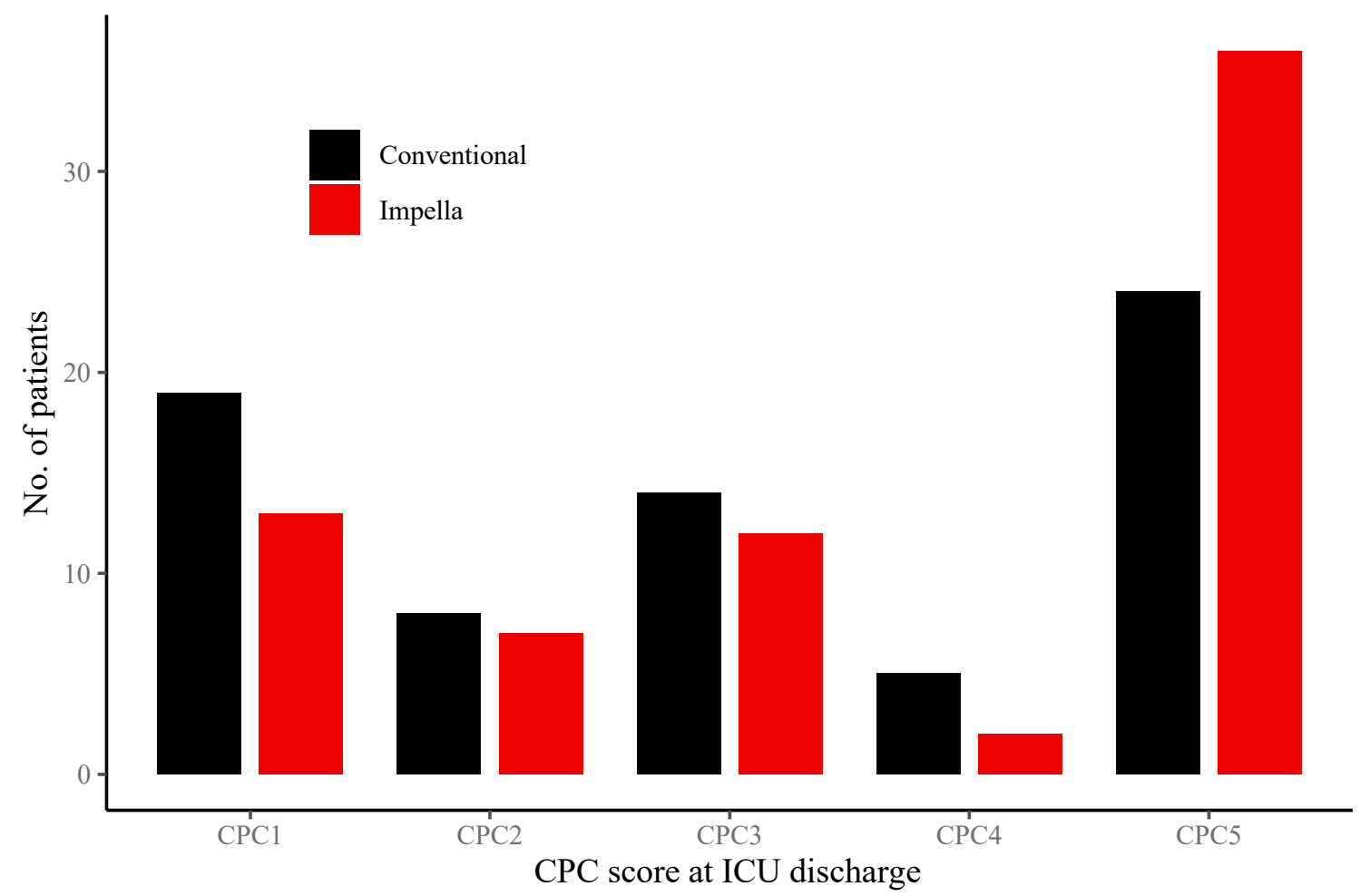

Figure 4. Neurologic outcome of patients treated without cardiocirculatory support versus patients treated Impella support. CPC scores at discharge of patients with no cardiocirculatory support (black) versus Impella support (red) $(p=0.28)$ are displayed.

Table 3. Clinical endpoints.

\begin{tabular}{|c|c|c|c|c|}
\hline Variables & $\begin{array}{c}\text { Conventional } \\
(n=70)\end{array}$ & Impella $(n=70)$ & $p$ Value (Paired) & $\begin{array}{c}p \text { Value } \\
\text { (Not Paired) }\end{array}$ \\
\hline CPC on discharge, $n(\%)$ & - & - & \multirow{6}{*}{ NA } & \multirow{6}{*}{0.28} \\
\hline $\mathrm{CPC} 1$ & $19(27.1)$ & $13(18.6)$ & & \\
\hline CPC2 & $8(11.4)$ & $7(10.0)$ & & \\
\hline СРC3 & $14(20.0)$ & $12(17.1)$ & & \\
\hline СPC4 & $5(7.1$ & $2(2.9)$ & & \\
\hline CPC5 & $24(34.3)$ & $36(51.4)$ & & \\
\hline Mortality rate after 30 days, $\%(95 \% \mathrm{CI})$ & $41.4(28.7,51.9)$ & $54.3(41.0,64.6)$ & \multicolumn{2}{|c|}{0.17} \\
\hline Mortality rate after one year, $\%$ (95\% CI) & $54.7(40.7,65.4)$ & $58.8(45.4,68.9)$ & \multicolumn{2}{|c|}{0.30} \\
\hline Mortality rate after 5 years, $\%(95 \% \mathrm{CI})$ & $64.4(47.6,75.8)$ & $72.5(56.9,82.5)$ & \multicolumn{2}{|c|}{0.33} \\
\hline Bleeding rate $\geq$ BARC $3, \%(95 \%$ CI $)$ & $14.7(5.2,23.2)$ & $43.1(27.0,55.7)$ & \multirow{2}{*}{\multicolumn{2}{|c|}{$\begin{array}{c}0.002 \\
<0.001\end{array}$}} \\
\hline Bleeding rate BARC1-5, $\%$ (95\% CI) & $37.3(23.8,48.5)$ & $74.1(58.1,84.0)$ & & \\
\hline Myocardial infarction during ICU stay, $n(\%)$ & $3(4.3)$ & $1(1.4)$ & 0.62 & 0.61 \\
\hline Stroke during ICU stay, $n(\%)$ & $1(1.4)$ & $4(5.7)$ & 0.37 & 0.36 \\
\hline Vascular complications during ICU stay, $n(\%)$ & $0(0.0)$ & $5(7.1)$ & 0.07 & 0.07 \\
\hline
\end{tabular}


Table 4. Cox proportional hazard regression for long term-survival.

\begin{tabular}{|c|c|c|c|c|c|c|}
\hline \multirow{2}{*}{ Risk Factor } & \multicolumn{3}{|c|}{ Univariate Analysis } & \multicolumn{3}{|c|}{ Multivariate Analysis after Feature Selection } \\
\hline & Hazard Ratio & $95 \% \mathrm{CI}$ & $p$ Value & Hazard Ratio & $95 \% \mathrm{CI}$ & $p$ Value \\
\hline Age [years] & 1.040 & $1.022-1.058$ & 0.000 & 1.046 & $1.026-1.067$ & $<0.001$ \\
\hline Diabetes & 1.216 & $0.786-1.880$ & 0.380 & - & - & - \\
\hline Hypertension & 1.642 & $1.005-2.685$ & 0.048 & - & - & - \\
\hline $\begin{array}{l}\text { First lactate measured on } \\
\text { ICU [per mmol/L] }\end{array}$ & 1.151 & $1.097-1.209$ & 0.000 & 1.099 & $1.034-1.168$ & 0.002 \\
\hline $\begin{array}{l}\text { First GFR measured on } \\
\text { ICU [per } \mathrm{mL} / \mathrm{min} \text { ] }\end{array}$ & 0.983 & $0.972-0.993$ & 0.001 & 0.987 & $0.975-1.000$ & 0.042 \\
\hline Cardiac arrest & 1.915 & $1.250-2.932$ & 0.003 & 1.887 & $1.096-3.249$ & 0.022 \\
\hline Impella treatment & 1.235 & $0.808-1.887$ & 0.330 & - & - & - \\
\hline Myocardial infarction & 1.374 & $0.826-2.287$ & 0.221 & - & - & - \\
\hline
\end{tabular}

\section{Discussion}

This study including cardiogenic shock patients treated with standard of care vs. mechanical circulatory support using Impella CP between 2010 and 2020 investigated long-term outcome and bleeding complications. The main findings of our study are as follows: (1) There was no statistically significant difference in 30-day, 1-year and 5 years mortality rate between both groups, (2) Impella CP treatment was accompanied with an almost tripled rate of clinical significant bleedings compared to the control group, and (3) the median length of ICU-stay was longer in the Impella CP group.

To the best of our knowledge, we here report the first investigation on long-term mortality of cardiogenic shock patients treated with standard of care vs. mechanical circulatory support using Impella CP. Several retrospective studies and large registries did not focus on cardiogenic shock including mostly patients in which Impella was used as "protection" device in high risk PCI [15]. And yet others did not focus on Impella CP by including different types of devices, namely Impella 2.5, CP, 5.0 and even Tandem Heart within their analysis [17-20,26-28]. In this regard, the Impella 2.5 is limited by its pump volume of only $2.5 \mathrm{l} / \mathrm{min}$ compared to the contemporary available $\mathrm{CP}$ and $\mathrm{CP}$ Smart Assist which are able to pump up to 3.5 to $4.0 \mathrm{l} / \mathrm{min}$. The drawback of Impella 5.0 is the need for surgical cutdown which largely limits its use in a salvage or emergency setting. In our analysis we exclusively focused on both, Impella CP and cardiogenic shock, and excluded patients undergoing concomitant VA-ECMO treatment [11].

In others trials-focusing on Impella CP and cardiogenic shock-mid-term follow-up is limited to a maximum between 70 days and 12 month $[14,18,19]$. Here, we expand the available follow up-time up to 5 years.

Our 30-day and 1-year mortality rates were 54\% and 59\% in the Impella group, respectively. This is slightly higher compared to the small randomized IMPRESS trial (24 patients on Impella) which compared treatment with Impella CP vs. intra-aortic balloon pump [13]) with reported 30-day mortality of $46 \%$ which might be attributed to the fact that our analysis is an all-comers trial. Our mortality rate is lower compared to Loehn et al. (73 patients on Impella CP) [14], who reported mortality at discharge of $64 \%$. Interestingly, in the latter trial pre-PCI implanted Impella CP treated patients showed a lower mortality rate of $50 \%$ compared to post-PCI Impella CP implantation who showed a much higher mortality rate of $77 \%$. In our center implantation of Impella CP was always performed post-PCI.

There is an ongoing debate if pre-implantation of Impella can reduce infarct size as shown in the Door-To-Unload in STEMI Pilot Trial (DTU-STEMI) [29]. In this trial, the authors compared a 30 min delay for LV-unloading implanting the Impella CP device before revascularization vs. Impella implantation followed by immediate revascularization. However, patients in the latter trial did not suffer from cardiogenic shock and the study lacked a standard of care arm. If this new concept of care can possibly improve outcome is currently tested in the ongoing prospective, multicenter, randomized, controlled open-label two-arm Primary Unloading and Delayed Reperfusion in ST-Elevation Myocardial Infarction: The STEMI-DTU Trial (NCT03947619). This trial might answer the question if a postponed re-vascularization of infarct related artery will cause harm. By now, 
our strategy of post-PCI implantation shows a mortality rate at 30-days (54\%) which is comparable to the pre-PCI implantation cohort of the study of Loehn et al. (52\%) [14].

Bleeding complication occur frequently with Impella treatment and were reported as high as in our trial [16]. Using such devices—with an almost mandatory need for therapeutic anticoagulation—require a constant vigilance to prevent severe bleedings associated with access site puncture. Hence, the high rate of bleeding complication remains one of the most important disadvantages of this device.

Interestingly, we observed a longer ICU stay (plus 2 days) in patients undergoing Impella CP treatment although the SAPS II score at admission, the rate of mechanical ventilation and cardiac arrest was well matched between groups. This longer treatment period does not translate in improvement of in-hospital and 30-day or long-term survival but might instead increase treatment costs of this already very expensive treatment strategy. Since most trials investigating Impella treatment lack a control group without any mechanical support, the prolonged ICU stay of the Impella CP group is a new finding. In the setting of this trial factors like left ventricular and neurologic function might have a greater impact on long term outcome compared to temporary circulatory support.

Mechanical circulatory support using Impella CP has still not been investigated in large, randomized trials. Hence, the results of the randomized, multicenter Danish-German Cardiogenic Shock trial (NCT01633502) are urgently needed to prove the efficacy in reducing mortality of this very expensive device. Furthermore, future analysis should aim at investigating the role of Impella CP as bridge to recovery, left ventricular assist devices and heart transplantation in patients in cardiogenic shock class B and C according to SCAI definition [30]. This study did not compare Impella CP vs. VA-ECMO treatment for cardiogenic shock. In contrast to Impella CP, VA-ECMO treatment is restricted to a limited number of tertiary care centers in many countries and according to the latest update on cardiogenic shock published in the European Heart Journal last year [10] - this device is rather used for treatment of most severe cardiogenic shock Type E defined by lactate $>5 \mathrm{mmol} / \mathrm{L}$ [30]. Correspondingly, median lactate on admission in ICU in both groups was $3 \mathrm{mmol} / \mathrm{L}$.

Limitations: This retrospective, observational, analysis investigates mechanical circulatory support with Impella $\mathrm{CP}$ in a small patient cohort, but is the first analysis investigating long-term follow up in cardiogenic shock patients and presents a control group without any mechanical circulatory support. The indication of implanting a mechanical support device was at the physician's discretion. We acknowledge that matching of groups from different treatment periods comes along with limitations inherent to such analysis. Differences between the two groups may not have been detectable due to the small sample size and the inherent heterogeneity of patients treated with Impella CP. Matching of patients can only decrease but not abrogate confounding factors, which may bias the results of this study. This study did not compare Impella CP vs. VA-ECMO treatment for cardiogenic shock.

\section{Conclusions}

In this small observational and non-randomized analysis no difference in long-term outcome between patients treated with Impella CP vs. guideline directed cardiogenic shock therapy without mechanical circulatory support could be detected. Care must be taken regarding the high rate of bleeding and vascular complications when using Impella CP. Large, adequately powered studies are urgently needed to investigate the efficacy and safety of Impella CP in cardiogenic shock.

Supplementary Materials: The following are available online at http://www.mdpi.com/2077-0383/9/12/3803/s1, Figure S1: Love plot. Love plot showing standardized mean differences of unadjusted parameters before and adjusted parameters after matching; Figure S2: Lactate levels. Lactate levels after ICU admission in patients treated without cardiocirculatory support versus patients treated with Impella CP (day 1: $p=0.57$, day 2: $p=0.91$, day 3: $p=0.26$, day 4: $p=0.36$, day 5: $p=0.47$ ); Figure S3. Lactate levels. Lactate levels in patients treated with Impella CP after implantation; Table S1. Patients' characteristics before matching; Table S2. Medication at ICU discharge. 
Author Contributions: C.S. (Clemens Scherer), E.L. and M.O. (Martin Orban) designed the study, interpreted data and wrote the manuscript. D.K., T.J.S., K.S., C.S. (Christopher Stremmel), M.O. (Mathias Orban), T.P., A.G., K.M., S.K., D.B., H.T., S.B. collected and analysed data and critically revised the manuscript. J.M., J.H., S.M. interpreted data and critically revised the manuscript. All authors have read and agreed to the published version of the manuscript.

Funding: This research received no external funding.

Conflicts of Interest: Martin Orban received speaker honoraria from Abbott Medical, AstraZeneca, Abiomed, Bayer vital, BIOTRONIK, Bristol-Myers Squibb, CytoSorbents, Daiichi Sankyo Deutschland, Edwards Lifesciences Services, Sedana Medical, outside the submitted work; Daniel Braun and Mathias Orban have received speaker honoraria from Abbott Vascular. Jörg Hausleiter received speaker honoraria and research support from Abbott Vascular and Edwards Lifesciences, outside the submitted work.

\section{References}

1. Thiele, H.; Zeymer, U.; Neumann, F.-J.; Ferenc, M.; Olbrich, H.-G.; Hausleiter, J.; Richardt, G.; Hennersdorf, M.; Empen, K.; Fuernau, G.; et al. Intraaortic Balloon Support for Myocardial Infarction with Cardiogenic Shock. N. Engl. J. Med. 2012, 367, 1287-1296. [CrossRef]

2. Thiele, H.; Zeymer, U.; Neumann, F.-J.; Ferenc, M.; Olbrich, H.-G.; Hausleiter, J.; De Waha, A.; Richardt, G.; Hennersdorf, M.; Empen, K.; et al. Intraaortic Balloon Pump in cardiogenic shock IIti. Intra-aortic balloon counterpulsation in acute myocardial infarction complicated by cardiogenic shock (IABP-SHOCK II): Final 12 month results of a randomised, open-label trial. Lancet 2013, 382, 1638-1645. [CrossRef]

3. Thiele, H.; Akin, I.; Sandri, M.; Fuernau, G.; De Waha, S.; Meyer-Saraei, R.; Nordbeck, P.; Geisler, T.; Landmesser, U.; Skurk, C.; et al. PCI Strategies in Patients with Acute Myocardial Infarction and Cardiogenic Shock. N. Engl. J. Med. 2017, 377, 2419-2432. [CrossRef]

4. Thiele, H.; Akin, I.; Sandri, M.; de Waha-Thiele, S.; Meyer-Saraei, R.; Fuernau, G.; Eitel, I.; Nordbeck, P.; Geisler, T.; Landmesser, U.; et al. One-Year Outcomes after PCI Strategies in Cardiogenic Shock. N. Engl. J. Med. 2018, 379, 1699-1710. [CrossRef] [PubMed]

5. Rathod, K.S.; Koganti, S.; Iqbal, M.B.; Jain, A.K.; Kalra, S.S.; Astroulakis, Z.; Lim, P.; Rakhit, R.; Dalby, M.; Lockie, T.; et al. Contemporary trends in cardiogenic shock: Incidence, intra-aortic balloon pump utilisation and outcomes from the London Heart Attack Group. Eur. Heart J. Acute Cardiovasc. Care 2017, 7, $16-27$. [CrossRef] [PubMed]

6. Scherer, C.; Kupka, D.; Stocker, T.J.; Joskowiak, D.; Scheuplein, H.; Schönegger, C.M.; Born, F.; Stremmel, C.; Lüsebrink, E.; Stark, K.; et al. Isoflurane Sedation in Patients Undergoing Venoarterial Extracorporeal Membrane Oxygenation Treatment for Cardiogenic Shock-An Observational Propensity-Matched Study. Crit. Care Explor. 2020, 2, e0086. [CrossRef]

7. Ponikowski, P.; Voors, A.A.; Anker, S.D.; Bueno, H.; Cleland, J.G.; Coats, A.J.; Falk, V.; Gonzalez-Juanatey, J.R.; Harjola, V.P.; Jankowska, E.A.; et al. Authors/Task Force M. 2016 ESC Guidelines for the diagnosis and treatment of acute and chronic heart failure: The Task Force for the diagnosis and treatment of acute and chronic heart failure of the European Society of Cardiology (ESC)Developed with the special contribution of the Heart Failure Association (HFA) of the ESC. Eur. Heart J. 2016, 37, 2129-2200. [PubMed]

8. Ibañez, B.; Halvorsen, S.; Roffi, M.; Bueno, H.; Thiele, H.; Vranckx, P.; Neumann, F.-J.; Windecker, S.; James, S. Integrating the results of the CULPRIT-SHOCK trial in the 2017 ESC ST-elevation myocardial infarction guidelines: Viewpoint of the task force. Eur. Heart J. 2018, 39, 4239-4242. [CrossRef]

9. Schäfer, A.; Werner, N.; Westenfeld, R.; Møller, J.E.; Schulze, P.C.; Karatolios, K.; Pappalardo, F.; Maly, J.; Staudacher, D.; Lebreton, G.; et al. Clinical scenarios for use of transvalvular microaxial pumps in acute heart failure and cardiogenic shock-A European experienced users working group opinion. Int. J. Cardiol. 2019, 291, 96-104. [CrossRef]

10. Thiele, H.; Ohman, E.M.; De Waha-Thiele, S.; Zeymer, U.; Desch, S. Management of cardiogenic shock complicating myocardial infarction: An update 2019. Eur. Heart J. 2019, 40, 2671-2683. [CrossRef]

11. Lüsebrink, E.; Orban, M.; Kupka, D.; Scherer, C.; Hagl, C.; Zimmer, S.; Luedike, P.; Thiele, H.; Westermann, D.; Massberg, S.; et al. Prevention and treatment of pulmonary congestion in patients undergoing veno-arterial extracorporeal membrane oxygenation for cardiogenic shock. Eur. Heart J. 2020, 41, 3753-3761. [CrossRef] [PubMed] 
12. Brunner, S.; Guenther, S.P.; Lackermair, K.; Peterss, S.; Orban, M.; Boulesteix, A.-L.; Michel, S.; Hausleiter, J.; Massberg, S.; Hagl, C. Extracorporeal Life Support in Cardiogenic Shock Complicating Acute Myocardial Infarction. J. Am. Coll. Cardiol. 2019, 73, 2355-2357. [CrossRef] [PubMed]

13. Ouweneel, D.M.; Eriksen, E.; Sjauw, K.D.; Van Dongen, I.M.; Hirsch, A.; Packer, E.J.; Vis, M.M.; Wykrzykowska, J.J.; Koch, K.T.; Baan, J.; et al. Percutaneous Mechanical Circulatory Support Versus Intra-Aortic Balloon Pump in Cardiogenic Shock After Acute Myocardial Infarction. J. Am. Coll. Cardiol. 2017, 69, 278-287. [CrossRef] [PubMed]

14. Loehn, T.; O’Neill, W.W.; Lange, B.; Pfluecke, C.; Schweigler, T.; Mierke, J.; Waessnig, N.; Mahlmann, A.; Youssef, A.; Speiser, U.; et al. Long term survival after early unloading with Impella $\mathrm{CP}((\mathrm{R}))$ in acute myocardial infarction complicated by cardiogenic shock. Eur. Heart J. Acute Cardiovasc. Care 2020, 9, 149-157. [CrossRef]

15. Amin, A.P.; Spertus, J.A.; Curtis, J.P.; Desai, N.; Masoudi, F.A.; Bach, R.G.; McNeely, C.; Al-Badarin, F.; House, J.A.; Kulkarni, H.; et al. The Evolving Landscape of Impella Use in the United States Among Patients Undergoing Percutaneous Coronary Intervention With Mechanical Circulatory Support. Circulation 2020, 141, 273-284. [CrossRef]

16. Schrage, B.; Ibrahim, K.; Loehn, T.; Werner, N.; Sinning, J.-M.; Pappalardo, F.; Pieri, M.; Skurk, C.; Lauten, A.; Landmesser, U.; et al. Impella Support for Acute Myocardial Infarction Complicated by Cardiogenic Shock. Circulation 2019, 139, 1249-1258. [CrossRef]

17. Lackermair, K.; Sattler, S.; Huber, B.; Grabmaier, U.; Weckbach, L.; Bauer, A.; Theiss, H.; Hausleiter, J.; Mehilli, J.; Massberg, S.; et al. Retrospective analysis of circulatory support with the Impella CPßdevice in patients with therapy refractory cardiogenic shock. Int. J. Cardiol. 2016, 219, 200-203. [CrossRef]

18. Ouweneel, D.M.; De Brabander, J.; Karami, M.; Sjauw, K.D.; Engström, A.E.; Vis, M.M.; Wykrzykowska, J.J.; Beijk, M.A.; Koch, K.T.; Baan, J.; et al. Real-life use of left ventricular circulatory support with Impella in cardiogenic shock after acute myocardial infarction: 12 years AMC experience. Eur. Heart J. Acute Cardiovasc. Care 2018, 8, 338-349. [CrossRef]

19. Rohm, C.L.; Gadidov, B.; Leitson, M.; Ray, H.E.; Prasad, R. Predictors of Mortality and Outcomes of Acute Severe Cardiogenic Shock Treated with the Impella Device. Am. J. Cardiol. 2019, 124, 499-504. [CrossRef]

20. Schiller, P.; Hellgren, L.; Vikholm, P. Survival after refractory cardiogenic shock is comparable in patients with Impella and veno-arterial extracorporeal membrane oxygenation when adjusted for SAVE score. Eur. Heart J. Acute Cardiovasc. Care 2018, 8, 329-337. [CrossRef]

21. Udesen, N.J.; Møller, J.E.; Lindholm, M.G.; Eiskjær, H.; Schäfer, A.; Werner, N.; Holmvang, L.; Terkelsen, C.J.; Jensen, L.O.; Junker, A.; et al. Rationale and design of DanGer shock: Danish-German cardiogenic shock trial. Am. Heart J. 2019, 214, 60-68. [CrossRef] [PubMed]

22. Thiele, H.; Schuler, G.; Neumann, F.J.; Hausleiter, J.; Olbrich, H.G.; Schwarz, B.; Hennersdorf, M.; Empen, K.; Fuernau, G.; Desch, S.; et al. Intraaortic balloon counterpulsation in acute myocardial infarction complicated by cardiogenic shock: Design and rationale of the Intraaortic Balloon Pump in Cardiogenic Shock II (IABP-SHOCK II) trial. Am. Heart J. 2012, 163, 938-945. [CrossRef] [PubMed]

23. Mehran, R.; Rao, S.V.; Bhatt, D.L.; Gibson, C.M.; Caixeta, A.; Eikelboom, J.; Kaul, S.; Wiviott, S.D.; Menon, V.; Nikolsky, E.; et al. Standardized Bleeding Definitions for Cardiovascular Clinical Trials: A consensus report from the bleeding academic research consortium. Circulation 2011, 123, 2736-2747. [CrossRef] [PubMed]

24. Ho, D.E.; Imai, K.; King, G.; Stuart, E.A. Matching as Nonparametric Preprocessing for Reducing Model Dependence in Parametric Causal Inference. Politi Anal. 2007, 15, 199-236. [CrossRef]

25. Sleeper, L.A.; Reynolds, H.R.; White, H.D.; Webb, J.G.; Džavík, V.; Hochman, J.S. A severity scoring system for risk assessment of patients with cardiogenic shock: A report from the SHOCK Trial and Registry. Am. Heart J. 2010, 160, 443-450. [CrossRef]

26. O'Neill, W.W.; Grines, C.; Schreiber, T.; Moses, J.; Maini, B.; Dixon, S.R.; Ohman, E.M. Analysis of outcomes for 15,259 US patients with acute myocardial infarction cardiogenic shock (AMICS) supported with the Impella device. Am. Heart J. 2018, 202, 33-38. [CrossRef]

27. Garan, A.R.; Takeda, K.; Salna, M.; Vandenberge, J.; Doshi, D.; Karmpaliotis, D.; Kirtane, A.J.; Takayama, H.; Kurlansky, P. Prospective Comparison of a Percutaneous Ventricular Assist Device and Venoarterial Extracorporeal Membrane Oxygenation for Patients With Cardiogenic Shock Following Acute Myocardial Infarction. J. Am. Heart Assoc. 2019, 8, e012171. [CrossRef] 
28. Seyfarth, M.; Sibbing, D.; Bauer, I.; Fröhlich, G.; Bott-Flügel, L.; Byrne, R.; Dirschinger, J.; Kastrati, A.; Schömig, A. A Randomized Clinical Trial to Evaluate the Safety and Efficacy of a Percutaneous Left Ventricular Assist Device Versus Intra-Aortic Balloon Pumping for Treatment of Cardiogenic Shock Caused by Myocardial Infarction. J. Am. Coll. Cardiol. 2008, 52, 1584-1588. [CrossRef]

29. Kapur, N.K.; Alkhouli, M.; DeMartini, T.J.; Faraz, H.; George, Z.H.; Goodwin, M.J.; Hernandez-Montfort, J.A.; Iyer, V.S.; Josephy, N.; Kalra, S.; et al. Unloading the Left Ventricle Before Reperfusion in Patients With Anterior ST-Segment-Elevation Myocardial Infarction. Circulation 2019, 139, 337-346. [CrossRef]

30. Baran, D.A.; Grines, C.L.; Bailey, S.; Burkhoff, D.; Hall, S.A.; Henry, T.D.; Hollenberg, S.M.; Kapur, N.K.; O'Neill, W.; Ornato, J.P.; et al. SCAI clinical expert consensus statement on the classification of cardiogenic shock: This document was endorsed by the American College of Cardiology (ACC), the American Heart Association (AHA), the Society of Critical Care Medicine (SCCM), and the Society of Thoracic Surgeons (STS) in April 2019. Catheter. Cardiovasc. Interv. 2019, 94, 29-37. [CrossRef]

Publisher's Note: MDPI stays neutral with regard to jurisdictional claims in published maps and institutional affiliations.

(C) 2020 by the authors. Licensee MDPI, Basel, Switzerland. This article is an open access article distributed under the terms and conditions of the Creative Commons Attribution (CC BY) license (http://creativecommons.org/licenses/by/4.0/). 